Advance Journal of Food Science and Technology 16(SPL) 7-12, 2018

DOI:10.19026/ajfst.16.5929

ISSN: 2042-4868; e-ISSN: 2042-4876

(C) 2018 Maxwell Scientific Publication Corp.

Submitted: September 13, $2017 \quad$ Accepted: November 24, $2017 \quad$ Published: November 10, 2018

\title{
Short communication \\ Prevalence of Bacteria Associated with Infectious Bovine Mastitis in Some Milk-Producing Municipalities in Norte de Santander Department
}

\author{
${ }^{1}$ Angela M. Cajiao, ${ }^{1}$ Liliana Rojas and ${ }^{2}$ Alfonso E. Capacho \\ ${ }^{1}$ Research Group on Microbiology and Biotechnology-GIMBIO-, Department of Microbiology, \\ Faculty of Basic Sciences, \\ ${ }^{2}$ Research Group on Sustainable Agriculture GIAS, Faculty of Agrarian Sciences, \\ University of Pamplona, Pamplona, Colombia
}

\begin{abstract}
A study was carried out to establish the prevalence of bacteria associated with infectious bovine mastitis in some milk-producing municipalities in Norte de Santander Department, from which possible species of Staphylococcus, Streptococcus and Enterobacteria were isolated and identified. One hundred and sixty three samples which were inoculated by depletion in: Blood Agar and EMB Agar were analyzed and incubated at $37^{\circ} \mathrm{C} / 24 \mathrm{~h}$. Preliminary identification of the bacteria was done through conventional biochemical tests and RapID ${ }^{\mathrm{TM}}$ ONE System and RapID System PLUS STAPH. A total of 207 bacteria were isolated; 187 isolates corresponded to: Staphylococcus aureus, S. capitis, S. epidermidis, S. haemolyticus, S. saprophyticus, S. simulans and S. xylosus. And 20 isolates to: Escherichia coli, Enterobacter agglomerans, Klebsiella pneumoniae, Shigella spp. and Acinetobacter calcoaceticus. Staphylococcus epidermidis showed the highest prevalence for Pamplona, Pamplonita and Toledo with 19.02, 21, 46 and 7.32\%, respectively. In Pamplona, the prevalence of Acinetobacter calcoaceticus and Shigella spp. with 0.49\%; Klebsiella pneumoniae and Shigella spp. were isolated in Pamplonita (0.49\%), in Toledo E. coli and Enterobacter agglomerans (1.95\%). The species isolated in this study have been described as causing mastitis in dairy cattle and their presence is related to cleaning conditions and milking practices.
\end{abstract}

Keywords: Enterobacteria, isolation, microorganisms, milk, Staphylococcus

\section{INTRODUCTION}

Bovine mastitis is the most frequent and costly disease that affects the dairy industry around the world (Correa and Marin, 2002; Cerón-Muñoz et al., 2002; Wellenberg et al., 2002) which describes an inflammatory reaction in the mammary gland caused by a spectrum of pathogens that penetrate the nipple canal (Kitchen, 1981; Chen et al., 2015). The severity of inflammation depends on the causative agent and the response of the host (Burvenich et al., 2003; Bannerman et al., 2004; Barkema et al., 2006; Petzl et al., 2008) producing pain and stress to the cows, resulting in a decrease in production and in the quality of the milk, as it changes it's taste and normal bacterial load increases. It also can be caused by physical injury, poor disinfection of the udders in the extraction process, mishandling of milking machines, postmilking sealing flaws and poor conditions of the room among other factors which predispose the entry of pathogenic microorganisms to the mammary glands causing physical damage to the tissue and inflammation (Acuña and Rivadeneira, 2008).

The mastitis is characterized by physical and chemical changes of the milk and pathophysiological breast tissue with possible systemic symptoms (EFSA, 2009). It is considered a complex disease product of the interaction of several factors: The animal, the environment, microorganisms and the human being (Valdivieso, 2008). The disease is caused by a wide variety of pathogenic organisms, including bacteria such as coagulase Staphylococcus spp., Streptococcus spp., Klebsiella spp. and Escherichia coli (Corpoica, 2012). Within other pathogens that cause the disease are: Streptococcus agalactiae, Streptococcus dysgalactiae, Streptococcus uberis, Pasteurella spp., Clostridium perfringens, Nocardia asteroides, Mycoplasma bovis, Corynebacterium pyogenes, Pseudomonas spp., Leptospira spp., Serratia spp. (Calvinho and Tirante, 2005; Gómez, 2008).

Taking into account its symptoms, mastitis can be divided into clinical and subclinical matters. In clinical

Corresponding Author: Angela M. Cajiao, Research Group on Microbiology and Biotechnology-GIMBIO-, Department of Microbiology, Faculty of Basic Sciences, University of Pamplona, Pamplona, Colombia, Tel.: (57+) 234685303

This work is licensed under a Creative Commons Attribution 4.0 International License (URL: http://creativecommons.org/licenses/by/4.0/). 
mastitis, the inflammation is present at the mammary glands, leading and a change of color, turning it yellow or red due to the presence of pus or blood. In severe cases can be seen and increased body temperature and pulse of the animal also decay, loss of appetite and decrease in production (Calderón et al., 2011).

Subclinical mastitis is considered as the most common mastitis in cows (Barlow et al., 2013) and involves inflammation in the mammary glands but not necessarily infection; it is characterized by the absence of clinical signs in the udder and the normal appearance of the milk. There are significantly higher levels of somatic cells in the milk from diseased glands with changes of physicochemical, microbiological and organoleptic characteristics but in the absence of inflammatory symptoms or systematic manifestations (Morales, 2011).

The inflammatory reaction can be identified by a high somatic cell count or other indirect measures of inflammation, such as the California Mastitis Test (CMT) (Dohoo et al., 2011). This type of mastitis is not evident without an analysis of production losses over a long period of time (a year or more), reason why it is difficult to take the control measurement decision (Andresen, 2001).

From a health point of view the bovine mastitis is important because the microorganisms can produce toxins that cause diseases to humans such as endocarditis, meningoencephalitis, enteritis and arthritis, representing a risk to human health (Insua et al., 2008). The etiology of the clinical and subclinical mastitis shows differences between regions and countries (Bradley and Green, 2009). Taking into account this behavior is essential to identify the microorganisms circulating before considering any control of the disease (Pitkälä et al., 2004).

It is likely that the prevalence of bovine mastitis in some towns of milk producers in Norte of Santander Department of Colombia is related to the lack of knowledge of farmers with regard to the implementation of good milking practices, hygiene and disinfection of the cow udders before and after the milking process. Therefore, this study aims to determine the prevalence and characterize phenotypically bacteria associated with infectious bovine mastitis in some milk-producing municipalities in Norte de Santander Department.

\section{MATERIALS AND METHODS}

Localization and sampling: The choice of municipalities where the study was conducted was based on its location in the regions: Southwest or province of Pamplona and southeast of Norte de Santander Department, Colombia, located in the northeast of the Andean region of the country; located between $06^{\circ} 56^{\prime} 42^{\prime}$ and $09^{\circ} 18^{\prime} 01^{\prime \prime}$ north latitude and $72^{\circ} 01^{\prime} 13^{\prime \prime}$ and $73^{\circ} 38^{\prime} 25^{\prime \prime}$ west longitude. These areas are characterized by herds with similar characteristics in terms of the type of feed and management system in general. On the other hand, it took into account the number of animals present in the herd in relation to the area to be sampled. The municipalities where samples were taken were Southwest region: Pamplona Pamplonita and the village of La Lejía; Southeast region: Toledo and Labateca.

The final sample was comprised of: 163 samples in two samplings, each of 81 samples which were taken in 15 farms from 5 municipalities.

Diagnosis of subclinical mastitis through California Mastitis Test (CMT): A sample was taken after discarding the first three squirts of milk, then a sample was taken from each quarter of the udder of the cow for each well of the paddle CMT; In each of the wells of the 2-3 mL of reagent was deposited of CMT (aryl alkyl sodium sulfonate), then $2-3 \mathrm{~mL}$ of milk were added, the mixture was stirred with circular movements for $10 \mathrm{sec}$ and then proceeded the reaction was analysed (Bolaños et al., 2012).

Bacterial diagnosis: Each sample was inoculated by exhaustion in: EMB Agar and blood agar and incubated at $37^{\circ} \mathrm{C}$ for $24 \mathrm{~h}$. Bacterial isolation was performed on blood agar, Mannitol Salt Agar, Baird Parker Agar, MacConkey and Agar, KF, according to their morphological characteristics and subsequently were incubated at $37^{\circ} \mathrm{C}$ for $24 \mathrm{~h}$. This condition was given to the previous crops with possibility to find Microeurophilic microorganisms. According to the characteristics of growth that were found, a ringing was performed to the nutrient medium and subsequently characterized phenotypically to corroborate by Gram staining the axenic crop and the reaction of microorganisms. Tests of coagulase-oxidase, catalase, were conducted, as well as tests were applied preliminary identification of bacteria by conventional biochemical such as (Urea, TSI, SIM, Lia, RMVP, Citrate, Nitrate, Gelatin, Motility, Mannitol, Sucrose, Dextrose, Lactose, Galactose, Arabinose and hydrolysis of Starch); the identification was complement with RapID $^{\text {TM }}$ ONE System and RapID SYSTEM PLUS STAPH.

The final sample consisted of: 163 samples, of which 96 (96) were taken in the municipalities from the Southwest area and (67) in municipalities in the Southeast area. In each of the municipalities, 15 farms were monitored.

Descriptive statistics were used for the analysis of the results; the statistical package SPSS version 10 was used.

\section{RESULTS AND DISCUSSION}

The results of the prevalence of bovine mastitis using the California Mastitis Test (CMT) are presented in Table 1. The results obtained from this test reveal that from 652 quarters sampled 303 were positive for subclinical mastitis. 
Adv. J. Food Sci. Technol., 16(SPL) 7-12, 2018

Table 1: Prevalence of mastitis in the Western Southwest zone and Southeast of the Norte de Santander department

\begin{tabular}{lllll}
\hline Zone & Municipality & Estate & CMT & Prevalence of bovine mastitis (\%) \\
\hline Southwest & Pamplona & 1 & 12 & 100 \\
& & 2 & 8 & 87.5 \\
& Pamplonita & 3 & 8 & 78 \\
& 1 & 2 & 12 & \\
Southeast & Village La Lejia & 3 & 8 & 94.11 \\
& & 1 & 8 & \\
& Toledo & 2 & 9 & 84.8 \\
& & 3 & 11 & \\
& Labateca & 2 & 11 & 88.95 \\
\end{tabular}

Table 2: Etiology of mastitis in the southwest zone and Southeast of the Norte de Santander department

\begin{tabular}{|c|c|c|c|c|}
\hline \multirow{27}{*}{$\frac{\text { Zone }}{\text { Southwest }}$} & Municipality & Microorganisms & Number of isolation & Isolation (\%) \\
\hline & \multirow[t]{10}{*}{ Pamplona } & S. epidermidis & 39 & 19.02 \\
\hline & & S. aureus & 7 & 3.41 \\
\hline & & S. haemolyticus & 6 & 2.93 \\
\hline & & S. capitis & 4 & 1.95 \\
\hline & & S. saprophyticus & 4 & 1.95 \\
\hline & & S. simulans & 4 & 1.95 \\
\hline & & S. xilosus & 4 & 1.95 \\
\hline & & Streptococcus spp. & 2 & 0.98 \\
\hline & & Acinetobacter calcoaceticus & 1 & 0.49 \\
\hline & & Shigella spp. & 1 & 0.49 \\
\hline & \multirow[t]{10}{*}{ Pamplonita } & S. epidermidis & 44 & 21.46 \\
\hline & & S. saprophyticus & 8 & 3.90 \\
\hline & & S. aureus & 6 & 2.93 \\
\hline & & S. haemolyticus & 6 & 2.93 \\
\hline & & S. cohnii & 4 & 1.95 \\
\hline & & S. simulans & 4 & 1.95 \\
\hline & & Streptococcus spp. & 2 & 0.98 \\
\hline & & S. capitis & 2 & 0.98 \\
\hline & & Klebsiella pneumoniae & 1 & 0.49 \\
\hline & & Shigella spp. & 1 & 0.49 \\
\hline & \multirow[t]{6}{*}{ Village La Lejia } & S. aureus & 2 & 0.98 \\
\hline & & Streptococcus spp. & 1 & 0.49 \\
\hline & & S. saprophyticus & 1 & 0.49 \\
\hline & & S. epidermidis & 1 & 0.49 \\
\hline & & S. simulans & 1 & 0.49 \\
\hline & & S. hominis & 1 & 0.49 \\
\hline \multirow[t]{19}{*}{ Southeast } & \multirow[t]{12}{*}{ Toledo } & S. epidermidis & 15 & 7.32 \\
\hline & & Klebsiella pneumoniae & 7 & 3.41 \\
\hline & & S. aureus & 4 & 1.95 \\
\hline & & E. agglomerans & 4 & 1.95 \\
\hline & & E. coli & 4 & 1.95 \\
\hline & & S. saprophyticus & 2 & 0.98 \\
\hline & & S. simulans & 2 & 0.98 \\
\hline & & Streptococcus spp. & 1 & 0.49 \\
\hline & & S. xilosus & 1 & 0.49 \\
\hline & & S. hominis & 1 & 0.49 \\
\hline & & S. haemolyticus & 1 & 0.49 \\
\hline & & S. capitis & 1 & 0.49 \\
\hline & \multirow{7}{*}{ Labateca } & Enterobacter spp. & 1 & 0.49 \\
\hline & & S. aureus & 1 & 0.49 \\
\hline & & S. epidermidis & 1 & 0.49 \\
\hline & & S. hominis & 1 & 0.49 \\
\hline & & S. saprophyticus & 1 & 0.49 \\
\hline & & S. simulans & 1 & 0.49 \\
\hline & & S. xilosus & 1 & 0.49 \\
\hline
\end{tabular}

A total disease prevalence of $88.95 \%$ (141 of 163 ) was obtained in both the Southwest and Southeastern areas of Norte de Santander Department, showing a very high percentage of affectation.

According to the average percentages of prevalence from the sampled municipalities in each zone, the following results were obtained: Southwest zone $88.5 \%$, zone Southeast zone $89.45 \%$ generating approximate results among them however, 652 cultures of milk samples were analyzed, which were from 163 cows, likewise, $33.33 \%$ of the samples did not show any growth. As shown in Table 2 . 


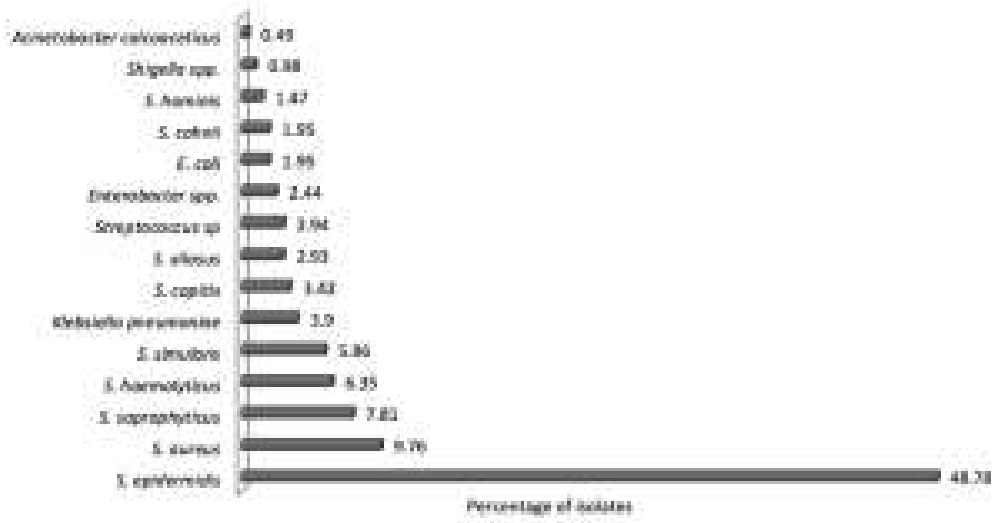

Fig. 1: Percentage of bacterial isolates associated with mastitis in the Westernsouth zone and Southeast of the North department of Santander

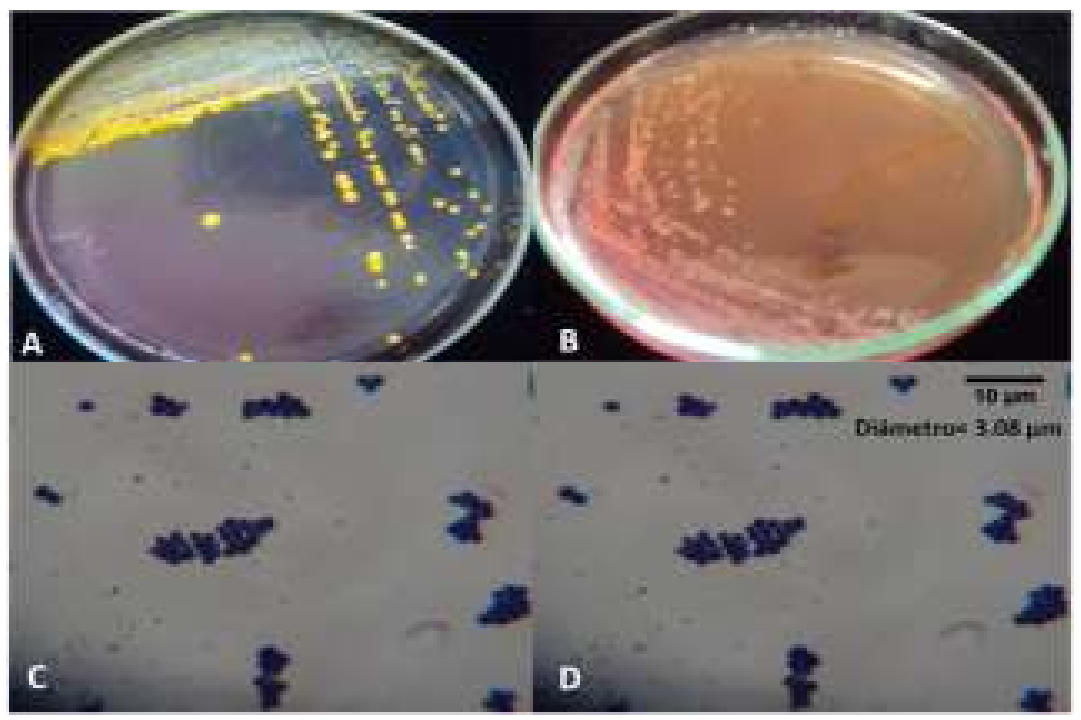

Fig. 2: Macroscopic and microscopic description of Staphylococcus spp., macroscopic and microscopic description of microorganisms belonging to the genus Staphylococcus, (A) Staphylococcus positive mannitol, (B) Staphylococcus negative mannitol, (C) Morphology microscopic, (D) Micrometry of the diameter of a colony of Staphylococcus, 100X lens

A total of 207 bacteria were isolated; as shown in Fig. 1, 157 isolates $(76.61 \%)$ corresponding to the Southwest zone of the Department and 50 isolates $(24.42 \%)$ to the Southeast area. In the municipality of Pamplona, 72 isolates were obtained, where 19.02\% corresponded to Staphylococcus epidermidis. In the municipality of Pamplonita, 78 isolates were found, where $21.46 \%$ were for S. epidermidis; while in the village of La Lejia with 7 isolates, $0.98 \%$ was for S. aureus.

As for the Southeastern region, 43 bacteria were isolated in the municipality of Toledo, where Staphylococcus epidermidis predominated with 7.32\% and in the municipality of Labateca 7 isolates corresponding to Enterobacter spp., $S$. aureus, S. epidermidis, S. hominis, S. saprophyticus, S. simulans and $S$. xilosus each with $0.49 \%$, respectively.
The most frequently isolated bacterium was Staphylococcus epidermidis (48.78\%), followed by Staphylococcus aureus (9.76\%).

In general, in the Southwest and Southeast regions, 187 isolates were obtained, corresponding to: Staphylococcus aureus, S. capitis, S. epidermidis, S. haemolyticus, S. saprophyticus, S. simulans, S. xylosus and Streptococcus spp. Figure 2, which are ubiquitous organisms and constitute the main component of the normal microbiota of the skin, mucous membranes and glands of mammals and other animals, also associated with infectious processes at these sites. Bonetto (2014) and Gomes (2013) establish a correlation between the presence of various species of the genus Staphylococcus spp. The results shown in mammary glands and infectious processes coincide with those reported by Thorberg et al. (2009) for the 


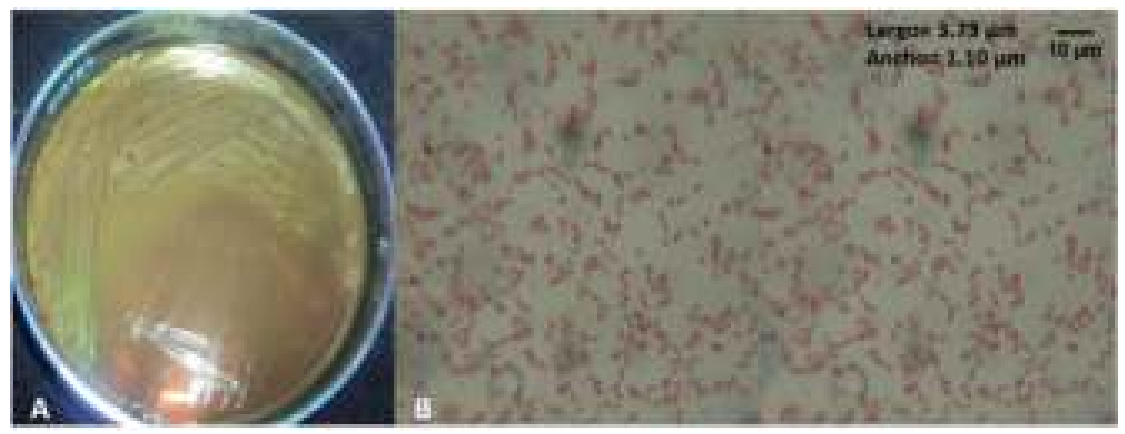

Fig. 3: Macroscopic and microscopic description of Escherichia coli, macroscopic and microscopic description of microorganisms belonging to the genus E. coli, (A) Macroscopic characteristics on EMB agar, (B) Morphology microscopic, (C) Micrometry of the diameter of E. coli, $100 \mathrm{X}$ lens

species S. epidermidis, S. aureus, S. saprophyticus, S. haemolyticus, S. simulans, S. capitis, S. xylosus which can present a strong inflammatory reaction measured by CMT.

On the other hand, Cucarella et al. (2002) mentioned biofilms in infections as an important concern because it protects microorganisms from leukocytes and antibiotics, leading to chronic infection and septicemia. Similar phenomena occur with other pathogenic bacteria, such as Klebsiella pneumoniae, Escherichia coli, among others. In this study a total of 20 microorganisms were isolated, corresponding to: Escherichia coli (Fig. 3), Enterobacter agglomerans, Klebsiella pneumoniae, Shigella spp. and Acinetobacter calcoaceticus.

\section{CONCLUSION}

The prevalence of infectious bovine mastitis was $88.95 \%$ (141 of 163) in both the Southwest and Southeastern areas of Norte de Santander Department; showing a very high percentage of affectation.

In this study the most prevalent bacteria were Staphylococcus epidermidis and Staphylococcus aureus, related to subclinical mastitis, according to CMT. Attention should be paid to prevalent and nonprevalent species given their ease in producing biofilms.

By finding normal biota from the skin of mammary glands in the milk samples, it suggests that the cleaning and disinfection processes during milking were not effective applied.

It was shown that that bovine mastitis prevalent in the municipalities of Pamplona, Pamplonita, villege La Lejia, Toledo and Labateca in Norte de Santander Department is due to the little knowledge that farmers have regarding the application of good practices of milking, hygiene and disinfection of the udders of cows before and after milking; in addition to what the disease is, how it is controlled and most important, how it is prevented.

\section{ACKNOWLEDGMENT}

The authors would like to thanks to the University of Pamplona, Faculty of Agricultural Sciences and Faculty of Basic Sciences for all the support.

\section{CONFLICT OF INTEREST}

The authors declare that there is no conflict of interest.

\section{REFERENCES}

Acuña, V. and A. Rivadeneira, 2008. Isolation, identification and antibiogram of pathogens present in milk with mastitis in bovine herds of the province of Pichincha. B.Sc. Thesis, Department of Agricultural Engineer, Polytechnic School of the Army, Career of Agricultural Sciences - I.A.S.A. I GRAL. Carlo Magno Andrade Paredes. Ecuador.

Andresen, H., 2001. Mastitis: Prevention and control. En. Rev. Inv. Vet. Perú.,12(2): 55-62.

Bannerman, D.D., M.J. Paape, J.W. Lee, X. Zhao, J.C. Hope and P. Rainard, 2004. Escherichia coli and Staphylococcus aureus elicit differential innate immune responses following intramammary infection. Clin. Diagn. Lab. Immunol., 11(3): 463-472.

Barkema, H.W., Y.H. Schukken and R.N. Zadoks, 2006. Invited Review: The role of cow, pathogen and treatment regimen in the therapeutic success of bovine Staphylococcus aureus mastitis. J. Dairy Sci., 89: 1877-1895.

Barlow, J.W., R.N. Zadoks and Y.H. Schukken, 2013. Effect of lactation therapy on Staphylococcus aureus transmission dynamics in two commercial dairy herds. BMC Vet. Res., 9: 28.

Bolaños, F., O. Fernando, T. Graffe, J. Eduardo, J.J. Peña, J. Cerquera and Y. Granja, 2012. Bovine mastitis: General and diagnostic methods. Vet. Electron. Mag., 13: 11. 
Bonetto, C.C., 2014. Bovine mastitis caused by coagulase negative Staphylococcus. Ph.D. Thesis, Department of Veterinary Sciences, Faculty of Veterinary Sciences, National University of La Plata, Cordoba, Argentina.

Bradley A.J. and M.J. Green, 2009. Factors affecting cure when treating bovine clinical mastitis with cephalosporin-based intramammary preparations. J. Dairy Sci., 92(5):1941-1953.

Burvenich, C., V. Van Merris, J. Mehrzad, A. DiezFraile and L. Duchateau, 2003. Severity of E. coli mastitis is mainly determined by cow factors. Vet. Res., 34(5): 521-564.

Calderón A.R., V.C.R. Rodríguez, G.B. Arrieta and S.V. Máttar, 2011. Prevalence of mastitis in dual purpose cattle farms in Monteria (Colombia): Etiology and antibacterial susceptibility. Revta Colomb. Cienc. Pec., 24: 19-28.

Calvinho, L.F. and L. Tirante, 2005. Prevalence of pathogenic microorganisms of bovine mastitis and evolution of the health status of the mammary gland in Argentina in the last 25 years. Rev. FAVE, 4(1-2): 29-40.

Cerón-Muñoz, M., H. Tonhati, J. Duarte, J. Oliveira, M. Muñoz-Berrocal and H. Jurado-Gámez, 2002. Factors affecting somatic cell counts and their relations with milk and milk constituent yield in buffaloes. J. Dairy Sci., 85(11): 2885-2889.

Chen, L., Y. Han, Y. Chen, Z. Li, H. Wang, Y. Liu, H. He, S. Chen and X. Liu, 2015. Eight SNVs in $\mathrm{NF}-\kappa \mathrm{B}$ pathway genes and their different performances between subclinical mastitis and mixed Chinese Holstein cows. Gene, 555(2): 242-249.

Corpoica, 2012. Bovine mastitis, infectious disease of great impact in dairy production. Colombian Corporation of Agricultural Research, Colombia. No. 26.

Correa, M.G. and J.M. Marin, 2002. O-serogroups, eae gene and EAF plasmid in Escherichia coli isolates from cases of bovine mastitis in Brazil. Vet. Microbiol., 85(2): 125-132.

Cucarella, C., M.A. Tormo, E. Knecht, B. Amorena, I. Lasa, T.J. Foster and J.R. Penadés, 2002. Expression of the biofilm-associated protein interferes with host protein receptors of Staphylococcus aureus and alters the infective process. Infect. Immun., 70(6): 3180-3186.
Dohoo, I.R., J. Smith, S. Andersen, D.F. Kelton and S. Godden, 2011. Diagnosing intramammary infections: Evaluation of definitions based on a single milk sample. J. Dairy Sci., 94(1): 250-261.

EFSA, 2009. Scientific report of farming systems on dairy cow welfare and disease. EFSA J., 11(43): $1-284$.

Gomes, M.J.P., 2013. Gênero Staphylococcus spp. Universidade Federal Do Rio Grande Do Sul. Brasil.

Gómez, R.G., 2008. Bovine mastitis. Bovine Encyclopedia. Editorial Committee of the FMVZ, National Autonomous University of Mexico (UNAM), Mexico.

Insua, D.A., C. Pérez and E. Silveira, 2008. Epizootiological evaluation of bovine mastitis in four dairy farms. Vet. Electron. Mag., 9(7): 1-9.

Kitchen, B.J., 1981. Review of the progress of dairy science: Bovine mastitis: Milk compositional changes and related diagnostic tests. J. Dairy Res., 48(1): 167-188.

Morales, L.H., 2011. Bovine mastitis: Biotechnology approach. Rev. Sci. Technol. Food Eng., 11(1b): 217-218.

Petzl, W., H. Zerbe, J. Günther, W. Yang, H.M. Seyfert, G. Nürnberg and H.J. Schuberth, 2008. Escherichia coli, but not Staphylococcus aureus triggers an early increased expression of factors contributing to the innate immune defense in the udder of the cow. Vet Res., 39(2): 18.

Pitkälä, A., M. Hayeri, S. Pyörälä, V. Myllys and T. Honkanen-Buzalski, 2004. Bovine mastitis in Finland 2001--Prevalence, distribution of bacteria and antimicrobial resistance. J. Dairy Sci., 87(8): 2433-2441.

Thorberg, B.M., M.L. Danielsson-Tham, U. Emanuelson and K. Persson Waller, 2009. Bovine subclinical mastitis caused by different types of coagulase-negative staphylococci. J. Dairy Sci., 92(10): 4962-4970.

Valdivieso, K.P., 2008. Study of the antimicrobial activity of nano silver on bovine subclinical mastitis in the Tunshi Production Unit. Ph.D. Thesis, Polytechnic School of Chimborazo, Ecuador.

Wellenberg, G.J., W.H. Van Der Poel and J.T. Van Oirschot, 2002. Viral infections and bovine mastitis: A review. Vet. Microbiol., 88(1): 27-45. 